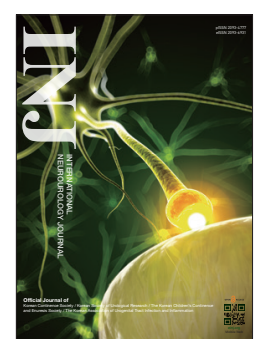

\title{
Noninvasive Medical Tools for Evaluating Voiding Pattern in Real
}

Life

\author{
Kwonsoo Chun ${ }^{1, *}$, Su Jin $\mathrm{Kim}^{2, *}$, Sung Tae Cho ${ }^{3}$ \\ ${ }^{1}$ Department of Pediatrics-Cardiology, Baylor College of Medicine, Houston, TX, USA \\ ${ }^{2}$ Department of Urology, Seoul St. Mary's Hospital, The Catholic University of Korea College of Medicine, Seoul, Korea \\ ${ }^{3}$ Department of Urology, Hallym University Kangnam Sacred Heart Hospital, Hallym University College of Medicine, Seoul, Korea
}

Voiding dysfunction is a common disease that contributes to a lower quality of life and has an increased prevalence in the elderly population. Noninvasive and objective methods such as uroflowmetry (UFM) and voiding diaries (VDs) are essential for exact diagnosis and effective treatment of this condition because patients with different causes of voiding dysfunction can complain of the same lower urinary tract symptoms. Further, different treatment options can be determined based on the diagnosis made from these symptoms. In order to improve the quality of UFM and VDs and to provide a convenient testing environment, several advances have been made by previous investigators. In this study, we investigate the history and technological mechanisms of UFM and VDs. We also aim to review UFM from the viewpoint of clinical and at-home uses, including the recently proposed toilet-shaped UFM and electronic VDs.

Keywords: Lower Urinary Tract Symptoms; Monitoring, Ambulatory; Mobile Health Units

- Fund/Grant Support: This work was supported by a National Research Foundation of Korea (NRF) grant funded by the Korea government (MSIP) (No. NRF-2014R1A2A1A11052321).

- Conflict of Interest: SJK, a member of the Editorial Board of INJ, is the co-first author of this article. However, she played no role whatsoever in the editorial evaluation of this article or the decision to publish it. No potential conflict of interest relevant to this article was reported.

\section{INTRODUCTION}

Voiding dysfunction is a common disease that contributes to a lower quality of life and has an increased prevalence in the elderly population [1]. Irwin et al. [2] have estimated the overall prevalence of voiding dysfunction in the world to be 2.3 billion in 2018. The common symptoms of voiding dysfunction are referred to as lower urinary tract symptoms (LUTS) and include frequent urination, weak urinary stream, residual urine sensation, urgency, hesitancy, intermittency, and nocturia [3]. Since
LUTS are important for suspecting and diagnosing voiding problems, an objective method for establishing the diagnosis is necessary. Patients with different causes of voiding dysfunction can complain of the same LUTS, despite of the different etiologies of the voiding dysfunction. Moreover, an accurate diagnosis is crucial because the treatment method should be selected according to the specific disease causing the voiding dysfunction. Voiding dysfunction can be caused by various diseases such as benign prostatic hyperplasia, overactive bladder (OAB), urinary incontinence, and neurogenic bladder $[4,5]$.
Corresponding author: Sung Tae Cho (iD https://orcid.org/0000-0002-4691-6159 Department of Urology, Hallym University Kangnam Sacred Heart Hospital, Hallym University College of Medicine, 1 Singil-ro, Yeongdeungpo-gu, Seoul 07441, Korea E-mail: cst326@paran.com / Tel: +82-2-846-5326 / Fax: +82-2-846-5198
This is an Open Access article distributed under the terms of the Creative Commons Attribution Non-Commercial License (http://creativecommons.org/licenses/by-nc/4.0/) which permits unrestricted non-commercial use, distri-
bution, and reproduction in any medium, provided the original work is properly cited.

*Kwonsoo Chun and Su Jin Kim contributed equally to this study as co-first authors. Submitted: March 20, 2017 / Accepted after revision: April 10, 2017 
Uroflowmetry (UFM) and voiding diaries (VDs) are useful clinical assessment tools to evaluate patients complaining of LUTS. They have been utilized to diagnose the cause of LUTS, determine treatment options, and predict clinical outcomes. UFM is a noninvasive test measuring the amount and speed of urination [6-8]. This test evaluates the physiological process of bladder emptying through the measurement of urine flow with UFM to identify the cause of the voiding dysfunction [4]. VDs helps to show the actual pattern of voiding and the related problems in real life because the subjective symptoms reported by patients can be more or less severe than the objective signs. Further, recording a VD helps to improve treatment outcomes because it can serve as a self-assessment, allowing the identification of changes after treatment [9-11]. Recently, researchers have been working on the development of portable medical devices that can be used in real life because such devices are expected to promote patients' compliance and the treatment effect. Moreover, portable and electronic UFM and VDs will be very helpful because they can determine a patient's status in real-life situations outside of a hospital.

Therefore, we reviewed the literature on the history and technological mechanisms of UFM and conventional VDs. Further, we aimed to review recent technological updates on toiletshaped UFM and electronic VDs.

\section{HISTORY OF UROFLOWMETER}

The first modern uroflowmeter was invented by an American surgeon named Willard M. Drake Jr. in 1946 [12]. The article about the this device was published in 1948 [13], and its patent (US 2,648,981) was granted in 1953. He designed the apparatus to reliably measure the time-volume relationship of micturition and prototyped the first flowmeter using a child's toy, an erector set, and a screen-door spring [13]. He designed for the urine to pass into a container suspended by a spring allowing for the weight of the urine to be monitored on a kymographic record as a function of time. In hundreds of UFM studies, he tried to determine the parameters of normal and abnormal flow and to establish a simple nomogram [12]. Kaufman [14] changed the uroflowmeter to have an electrical starting mechanism. Von Garrelts [15] simplified the equipment by including a commode and a flowmeter with the ability to measure the flow rate derived electronically from the flow curve.

\section{TYPES OF UROFLOWMETERS AND INTERPRETATION OF MEASUREMENT PARAMETERS}

Commercially available conventional uroflowmeters are based on a weight transducer, dipstick or rotating disc [16]. Weight transducers measure the volume or mass of the urine voided and this measurement is converted into the flow rate. The most widely used weight transducer is the load cell. The dipstick uroflowmeter uses a vertical dipstick, which changes its electrical capacitance depending on the level to which it is submerged in urine. The height of the collected urine is measured, the voided volume is calculated, and the flow rate is derived. The rotating disc measures the power necessary to maintain a constant rotation; since urine tends to slow down the speed of the disc, the additional power reflects the urine flow rate.

As shown in Fig. 1, the recoded profile of the urine flow for UFM is displayed as a graph of the flow rate $(\mathrm{mL} / \mathrm{sec})$ against time (sec). In general, normal patients demonstrate a bellshaped curve. The time profile of the urinary flow rate is analyzed, and the major measurement parameters for UFM, which have been standardized by the International Continence Society (ICS) are the maximal flow rate (Qmax), voided volume (Vvoid), average flow rate (Qave), flow time, and the time to maximum flow [17]. Qmax and Qave are defined as the maximum measured value of the flow rate and as the voided volume divided by the flow time, respectively [3]. Qmax is generally considered a clinically important parameter because it is used for screening and follow-up with patients to diagnose voiding

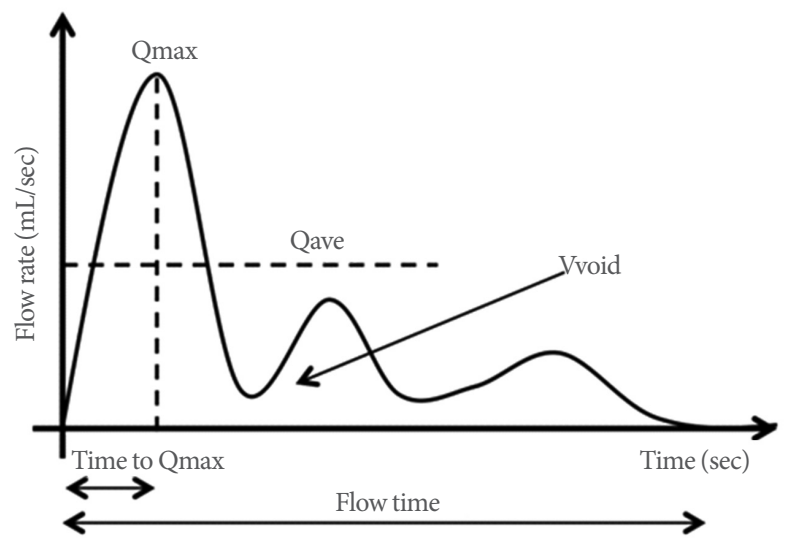

Fig. 1. The uroflow curve. Qmax, maximal flow rate; Vvoid, voided volume; Qave, average flow rate; flow time, time to void in seconds; time to Qmax; time to reach Qmax in seconds. 
dysfunctions such as bladder outflow obstruction as well as to investigate patient improvement after medical treatment such as bladder surgery $[18,19]$.

\section{HOME UROFLOWMETERS}

Routine UFM is generally performed in the clinic. However, clinic-based measurements are often inconvenient because patients need to stay at the clinic for several hours to fill their bladder and then urinate. Further, this behavior may not able to reproduce typical, ordinary voiding. An alternative solution to clinic-based tests is to allow patients to measure their urinary activity at home [20]. The simplest method to do so is to investigate the voided volume over a given time or inversely measuring time to void a given urinary volume $[21,22]$. From these values, the average flow rate can be calculated and manually documented. However, this method does not provide information about Qmax. In order to estimate Qmax, hand-held funnel devices have been introduced. Patients void into the funnel which has a restricted hole, and the urine drains through this hole into a volume-measurable container for the voided volume. Because of the restriction of the funnel hole, the urine level increases during voiding; this allows for the measurement of Qmax at the maximum level in the funnel [20]. The Qmax threshold can be calibrated and if the urine does not reach the threshold level during voiding, an abnormally abnormal low $\mathrm{Qmax}$ is present $[23,24]$.

\section{Uflow Meter}

Uflow Meter (MDTi, Wolverhampton, UK) is a commercially available funnel device. As illustrated in Fig. 2A, it has a funnel consisting of progressively narrower chambers and multiple holes. The diameter of the apertures is calibrated to indicate the following 3 ranges of Qmax: $<10 \mathrm{~mL} / \mathrm{sec}, 10-15 \mathrm{~mL} / \mathrm{sec}$, and $>$ $15 \mathrm{~mL} / \mathrm{sec}$ [25].

\section{Peakometer and CaptiFlow}

Peakometer shown in Fig. 2B uses electronic dipstick technology $[26,27]$ and monitors the urine level in the container. It automatically stores the Qmax information, while manual documentation is required for the voided volume through a visual inspection of the urine level by a user. In addition to the Peakometer, the portable CaptiFlow which is a similar in concept to the Peakometer, has recently been introduced [28].

\section{P-flow Meter}

An electronic portable home-based uroflowmeter, the P-flow meter, was developed by De la Rosette et al. [29]. This handheld device shown in Fig. $2 \mathrm{C}$ consists of 4 cup-shaped volume sensors printed on a disposable paper-like material. This device monitors changes in the electrical properties of the sensors caused by the urine, allowing the measurement of the urine volume and flow. Three small batteries are included to supply power, and the device has an electrical capacity high enough to operate several flow sessions. A microprocessor is embedded to control the sensors and the other electronics as well as to record flow measurements and time data into memory, incorporating a real-time clock.

\section{$Q_{\text {single }}$}

$\mathrm{Q}_{\text {single }}$ (AstraTech AB, Mölndal, Sweden) was developed as a single-use UFM device for home use in order to provide simple Qmax and Vvoid measurements [30]. As illustrated in Fig. 2D,
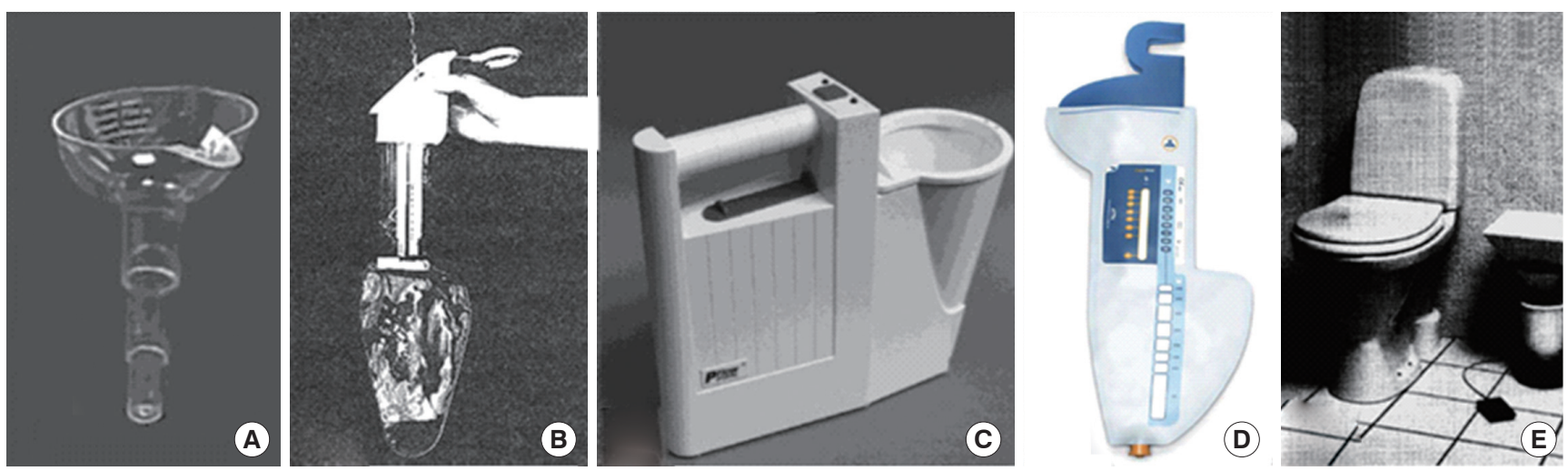

Fig. 2. Uroflowmeters. (A) Uflow Meter (MDTi, Wolverhampton, UK) [20], (B) Peakometer [20], (C) P-flow meter [20], (D) Qsingle device (AstraTech AB, Mölndal, Sweden) [30], and (E) Da Capo [20]. 
the device has stepwise indicators for describing the results. Increments in Qmax from 0 to $17 \mathrm{~mL} / \mathrm{sec}$ are displayed. Further, $\mathrm{Q}_{\text {single }}$ includes a container with a printed scale that can measure Vvoid in the range of 50 and $600 \mathrm{~mL}$.

\section{Da Capo}

The Da Capo uroflowmeter using a weight transducer was initially developed for clinical use and later adapted for at-home use $[20,31]$. It is a portable, battery-powered flowmeter designed to measure the voided volume versus time for a single patient. It includes a disposable container and funnel along with a foot switch, which is used for activating the flowmeter.

However, the above mentioned UFMs, have some limitations with respect to their application in real-life situations. The early at-home UFMs required manual documentation of the results by patients. These results measured manually by the patient were not considered to be accurate because a bias could interfere with the results. Therefore, we can conclude that the early at-home UFMs are not objective methods that reflect the real voiding status of the patients. Recently, electronic UFMs have been introduced that do not require patients to document results, but the UFMs must be brought to the clinic for the saved data to be read. Further, the above mentioned UFMs cannot be used in all populations. The earlier types of UFM (Fig. 2) are applicable to the male population, but female, children, elderly, and disabled people cannot use these devices because of physical limitations.

\section{TOILET UROFLOWMETRY}

Even though a UFM examination can be conducted at home, patients may experience some inconvenience due to the differences between home-use UFMs and toilets. Further, the urine measured using the conventional UFMs must be disposed outside the measurement container, increasing the possibility that the hands of the patients may come into contact with the collected urine. Therefore, UFM using a common toilet was introduced to overcome the potential inconvenience and risk of insanitation.

Toto Ltd., a well-known Japanese company manufacturing and selling toilets has come up with ideas for UFM utilizing toilet technology. Table 1 describes the intellectual property patents that Toto has filed for UFM. The first patent application (JP2004170331A) filed in 2002 was to provide a device for urine testing, which could inform patients of the urination amount while using an existing stool and urine test apparatus. Applications (JP2004-279199A and JP2004-278107A) filed in 2003 proposed inexpensive toilet bowl devices capable of measuring the urinary volume. A toilet system (JP2005-172647A, filed in 2003) included a weight-measuring mechanism. As patients measured their weight before and after excretion, this apparatus provided more biological information by monitoring the actual effects of excretion. To reduce the risk of water leakage accidents, an ultrasound system (JP2009-221794A) was suggested to measure urine flow information, such as a urine quantity and the urine flow rate. Patents were granted (JP-4217880B2 and JP4872432B2) for inventions to maintain a good sanitary environment in the toilet bowl and to avoid the bad emanating from the urine stored for examination.

The toilet-shaped UFM (UM-100, Toto Ltd., Fukuoka, Japan) shown in Fig. 3 was commercially developed in 2008 and was initially designed for clinical use. A major benefit of this

Table 1. Intellectual properties on uroflowmeterwhich Toto Ltd., Japan possesses

\begin{tabular}{lll}
\hline Patent No. & Filing date & Title of invention \\
\hline JP2009-221794A & 2008.03 .18$. & Urine flow measuring toilet bowl \\
JP4217880B2 & 2003.04 .22$. & biological information measuring system \\
JP2004-278107A & 2003.03 .14$. & Toilet bowl device \\
JP4872432B2 & 2006.04 .17$. & Biological information measuring toilet bowl \\
JP4415368B2 & 2003.06 .18$. & Device for measuring amount of urination \\
JP5601051B2 & 2010.07 .01$. & Device for collecting urine \\
JP2004-279199A & 2003.03 .14$. & Toilet bowl device \\
JP2005-24267A & 2003.06 .30$. & Biological information measuring device \\
JP2005-172647A & 2003.12 .12$. & Biological information measuring system at toilet seat \\
JP2004-170331A & 2002.11 .22$. & Urine test apparatus \\
\hline
\end{tabular}


system is that it allows patients to perform UFM by urinating in the toilet ordinarily [32]. A water-level measurement unit is installed in parallel to the toilet, as illustrated in Fig. 4A. The water level of the measurement unit is the same as that of the toilet. Urination leads to the elevation of the water level in the toilet, as shown in Fig. 4B, and the water level of the measurement unit increases because of pressure balancing. The water-level sensor monitors the change in the water level and provides the

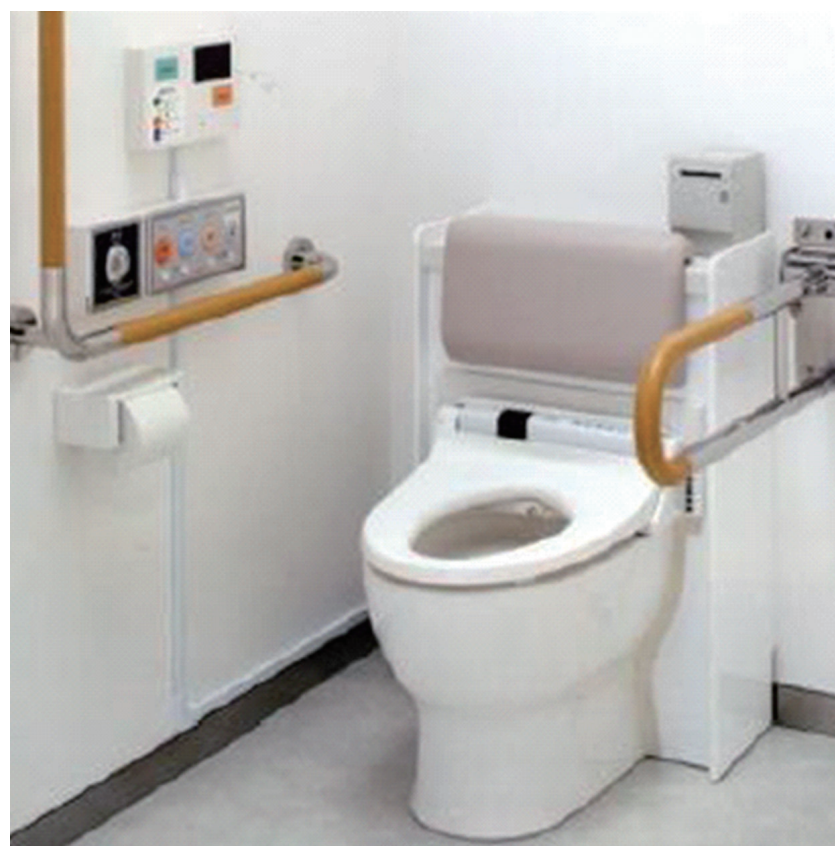

Fig. 3. Toilet-shaped uroflowmeter (UM-100, Toto Ltd., Fukuoka, Japan) [32].
UFM parameters. Because all in the toilet and the water level measurement unit are drained together completely and then refilled with fresh water, the system remains clean, as shown in Fig. 4C. However, since the system monitors the change in the total volume, it may have difficulties in isolating the effect of urination when patients pass stool and urinate together.

\section{VOIDING DIARIES FOR THE EVALUATION OF LUTS}

VDs is regarded as an accurate diagnostic method to define an objective signs from the subjective symptoms that patients complain of LUTS. The ICS introduced 3 types of diaries to record micturition and the symptoms: (1) a micturition time chart that records only the micturition time for at least 24 hours, (2) a frequency volume chart that records the micturition time with the volume voided at each micturition for at least 24 hours, (3) VD (also known as a bladder diary) that records the micturition time with the voided volumes, incontinence episodes, pad usage, fluid intake, the degree of urgency and incontinence [3]. Among the 3 types of diaries, VDs are commonly used for people of all ages, including children and the elderly, and their usefulness is well known. The recommended duration of VD is 3 days or more to ensure reliability [33]. At the same time, the completion of VD by a patient is important, and a relatively long period decreases patient's compliance [34]. Therefore, a 3-day VD is usually used for evaluating a patient's symptoms. In fact, VD analysis helps to identify specific types of nocturia and can help to treat the patient according to the

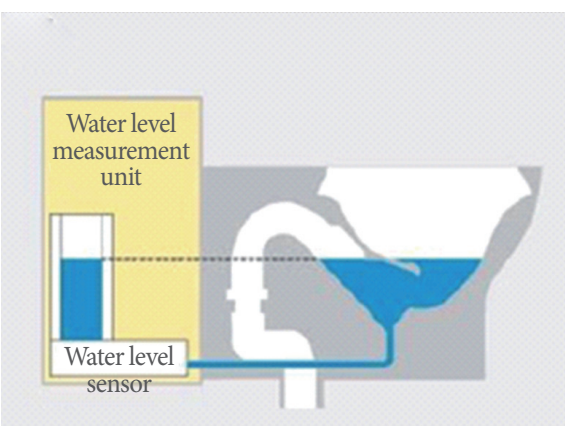

(A)

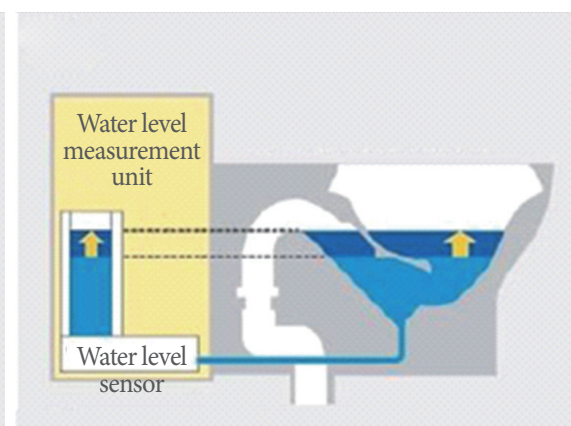

(B)

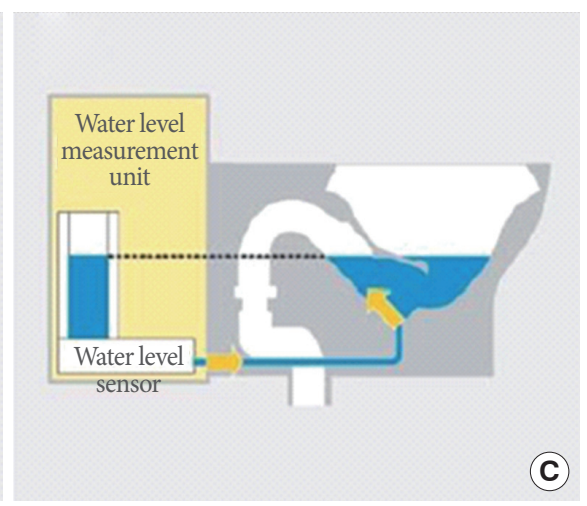

Fig. 4. Measurement mechanism of the toilet-shaped uroflowmeter (UM-100, Toto Ltd., Fukuoka, Japan). (A) When the device is installed, the water level measurement unit (water level sensor) learns the relationships between the water level and water volume, (B) The device converts the change of water level due to urination into the urine flow rate and the volume of urination, (C) The inside of measurement unit is cleaned when the toilet bowl is cleaned [32]. 
type of nocturia [35]. Further, it has been used widely for the diagnosis of $\mathrm{OAB}$ in men and women, urinary incontinence in the elderly, and children's nocturia and voiding problems [3638]. Despite these merits of VDs. some patients have shown poor compliance with paper-based VDs $[39,40]$. Therefore, electronic VDs were introduced.

\section{ELECTRONIC VOIDING DIARIES}

Compu-Void developed by Rabin et al. [41] was the first form of electronic VD to overcome low patient compliance with paper-based VD and the related inconveniences. Compu-Void is a primitive form of electronic VD, and patients used it after downloading programs onto a personal computer. Significantly high patient compliance and information accuracy were reported for this device. Since then, research on the development of electronic VDs has been progress. A study of women with $\mathrm{OAB}$ using a portable electronic data-capturing device revealed that similar data were recorded, and a majority of the patients felt that the electronic VD was easy to use [40]. Further, the device analyzed the data entered by the patients in real time. According to a study comparing the efficacy between an paper diary read electronically and an e-diary made with a touch screen device similar to a smartphone, patients preferred the e-diary [42]. As people are accustomed to mobile devices, electronic VDs are expected to become more popular. Further, for clinicians, the accuracy of interpreting data in real time is more helpful for diagnosis and treatment.

\section{CONCLUSION}

UFM and VDs are useful and noninvasive methods assisting in the diagnosis of LUTS or voiding dysfunction. To improve the quality of a UFM examination and provide a convenient testing environment to patients, home UFMs and toilet UFMs have been developed. Electronic VDs provide more accurate data about urination patterns and their interpretation in real life. Further, the user-friendly form of recent electronic VDs makes them easy to use from the perspective of both patients and clinicians. Therefore, the combination of recent UFM devices and electronic VDs reflective of real-life situations is expected to play an important role in the diagnosis and treatment of patients with voiding dysfunction.

\section{REFERENCES}

1. Kim TH, Han DH, Ryu DS, Lee KS. The impact of lower urinary tract symptoms on quality of life, work productivity, depressive symptoms, and sexuality in Korean men aged 40 years and older: a population-based survey. Int Neurourol J 2015;19:120-9.

2. Irwin DE, Kopp ZS, Agatep B, Milsom I, Abrams P. Worldwide prevalence estimates of lower urinary tract symptoms, overactive bladder, urinary incontinence and bladder outlet obstruction. BJU Int 2011;108:1132-8.

3. Abrams P, Cardozo L, Fall M, Griffiths D, Rosier P, Ulmsten U, et al. The standardisation of terminology of lower urinary tract function: report from the Standardisation Sub-committee of the International Continence Society. Neurourol Urodyn 2002;21:167-78.

4. Schafer W, Abrams P, Liao L, Mattiasson A, Pesce F, Spangberg A, et al. Good urodynamic practices: uroflowmetry, filling cystometry, and pressure-flow studies. Neurourol Urodyn 2002;21:261-74.

5. Kelly CE. Evaluation of voiding dysfunction and measurement of bladder volume. Rev Urol 2004;6 Suppl 1:S32-7.

6. van Venrooij GE, Eckhardt MD, Boon TA. Noninvasive assessment of prostatic obstruction in elderly men with lower urinary tract symptoms associated with benign prostatic hyperplasia. Urology 2004;63:476-80.

7. Oelke M, Hofner K, Jonas U, de la Rosette JJ, Ubbink DT, Wijkstra H. Diagnostic accuracy of noninvasive tests to evaluate bladder outlet obstruction in men: detrusor wall thickness, uroflowmetry, postvoid residual urine, and prostate volume. Eur Urol 2007;52: 827-34.

8. Alyami F, Farhat W, Figueroa VH, Romao RL. Utility and cost-effectiveness of uroflowmetry in a busy pediatric urology practice. Can Urol Assoc J 2014;8:E615-8.

9. Song M, Chun JY, Yoo DS, Han JY, Choo MS. Correlation of the overactive bladder symptom score, and the voiding diary and urodynamic parameters in patients with overactive bladder syndrome. Low Urin Tract Symptoms 2014;6:180-4.

10. Van Herzeele C, Evans J, Eggert P, Lottmann H, Norgaard JP, Vande Walle J. Predictive parameters of response to desmopressin in primary nocturnal enuresis. J Pediatr Urol 2015;11:200.e1-8.

11. Cho SY, Lee KS, Kim JH, Seo JT, Choo MS, Kim JC, et al. Effect of combined systematized behavioral modification education program with desmopressin in patients with nocturia: a prospective, multicenter, randomized, and parallel study. Int Neurourol J 2014; 18:213-20.

12. Chancellor MB, Rivas DA, Mulholland SG, Drake WM Jr. The invention of the modern uroflowmeter by Willard M. Drake, Jr at Jefferson Medical College. Urology 1998;51:671-4. 
13. Drake WM Jr. The uroflometer; an aid to the study of the lower urinary tract. J Urol 1948;59:650-8.

14. Kaufman JJ. A new recording uroflometer: a simple automatic device for measuring voiding velocity. J Urol 1957;78:97-103.

15. Von Garrelts B. Analysis of micturition; a new method of recording the voiding of the bladder. Acta Chir Scand 1957;112:326-40.

16. Addla SK, Marri RR, Daayana SL, Irwin P. Avoid cruising on the uroflowmeter: evaluation of cruising artifact on spinning disc flowmeters in an experimental setup. Neurourol Urodyn 2010;29:1301-5.

17. Stohrer M, Goepel M, Kondo A, Kramer G, Madersbacher H, Millard $\mathrm{R}$, et al. The standardization of terminology in neurogenic lower urinary tract dysfunction: with suggestions for diagnostic procedures. International Continence Society Standardization Committee. Neurourol Urodyn 1999;18:139-58.

18. McConnell JD, Roehrborn CG, Bautista OM, Andriole GL Jr, Dixon CM, Kusek JW, et al. The long-term effect of doxazosin, finasteride, and combination therapy on the clinical progression of benign prostatic hyperplasia. N Engl J Med 2003;349:2387-98.

19. McLoughlin J, Gill KP, Abel PD, Williams G. Symptoms versus flow rates versus urodynamics in the selection of patients for prostatectomy. Br J Urol 1990;66:303-5.

20. Bray A, Griffiths C, Drinnan M, Pickard R. Methods and value of home uroflowmetry in the assessment of men with lower urinary tract symptoms: a literature review. Neurourol Urodyn 2012;31:7-12.

21. Hansen MV, Zdanowski A. The use of a simple home flow test as a quality indicator for male patients treated for lower urinary tract symptoms suggestive of bladder outlet obstruction. Eur Urol 1997; 32:34-8.

22. Schwartz BF, Soderdahl DW, Thrasher JB. Home flow rates in evaluation of lower urinary tract symptoms in men. Tech Urol 1998;4: 15-7.

23. Smith JC. An individual uroflowmeter. Lancet 1965;1:90.

24. Currie RJ. The Streamtest cup: a new uroflow device. Urology 1998; 52:1118-21.

25. Pridgeon S, Harding C, Newton D, Pickard R. Clinical evaluation of a simple uroflowmeter for categorization of maximum urinary flow rate. Indian J Urol 2007;23:114-8.

26. Ball AJ. The peakometer: an evaluation. Urol Int 1982;37:42-4.

27. Drach GW, Binard W. Disposable peak urinary flowmeter estimates lower urinary tract obstruction. J Urol 1976;115:175-9.

28. Lucas M. Accuracy of CaptiFlow portable home flow measuring device and its use as a diagnostic tool in the management of LUTS - A randomised cross over study, In: International Continence Society Annual Meeting; 2009 Sept 29-Oct 3; San Francisco (CA), USA. Nondiscussion poster No. 400.
29. De La Rosette JJ, Witjes WP, Debruyne FM, Kersten PL, Wijkstra H. Improved reliability of uroflowmetry investigations: results of a portable home-based uroflowmetry study. Br J Urol 1996;78:385-90.

30. Heesakkers J, Farag F, Pantuck A, Moore K, Radziszewski P, Lucas M. Applicability of a disposable home urinary flow measuring device as a diagnostic tool in the management of males with lower urinary tract symptoms. Urol Int 2012;89:166-72.

31. Jørgensen JB, Jacobsen HL, Bagi P, Hvarnes H, Colstrup H. Home uroflowmetry by means of the Da Capo home uroflowmeter. Eur Urol 1998;33:64-8.

32. Izumi H, Nakagawa H, Kaiho Y, Miyazato M, Kawamorita N, Arai Y. Difference of uroflow parameters between novel toilet-shaped uroflowmeter (water level sensor mechanism) and conventional uroflowmeter in urologically normal female patients. In: International Continence Society Annual Meeting; 2011 Aug 29-Sept 2; Glasgow, United Kingdom. Nondiscussion poster No. 613.

33. Yap TL, Cromwell DC, Emberton M. A systematic review of the reliability of frequency-volume charts in urological research and its implications for the optimum chart duration. BJU Int 2007;99:9-16.

34. Groutz A, Blaivas JG, Chaikin DC, Resnick NM, Engleman K, Anzalone D, et al. Noninvasive outcome measures of urinary incontinence and lower urinary tract symptoms: a multicenter study of micturition diary and pad tests. J Urol 2000;164(3 Pt 1):698-701.

35. Weiss JP. Nocturia: “do the math”. J Urol 2006;175(3 Pt 2):S16-8.

36. Brown JS, McNaughton KS, Wyman JF, Burgio KL, Harkaway R, Bergner D, et al. Measurement characteristics of a voiding diary for use by men and women with overactive bladder. Urology 2003;61: 802-9.

37. Locher JL, Goode PS, Roth DL, Worrell RL, Burgio KL. Reliability assessment of the bladder diary for urinary incontinence in older women. J Gerontol A Biol Sci Med Sci 2001;56:M32-5.

38. Nascimento Fagundes S, Azevedo Soster L, Lebl AS, Rodrigues Pereira RP, Tanaka C, Pereira RF, et al. Impact of a multidisciplinary evaluation in pediatric patients with nocturnal monosymptomatic enuresis. Pediatr Nephrol 2016;31:1295-303.

39. Stone AA, Shiffman S, Schwartz JE, Broderick JE, Hufford MR. Patient non-compliance with paper diaries. BMJ 2002;324:1193-4.

40. Quinn P, Goka J, Richardson H. Assessment of an electronic daily diary in patients with overactive bladder. BJU Int 2003;91:647-52.

41. Rabin JM, McNett J, Badlani GH. Computerized voiding diary. Neurourol Urodyn 1993;12:541-53.

42. Mangera A, Marzo A, Heron N, Fernando D, Hameed K, Soliman $\mathrm{AH}$, et al. Development of two electronic bladder diaries: a patient and healthcare professionals pilot study. Neurourol Urodyn 2014; 33:1101-9. 